\title{
Frequency of Depression among Patients with Backache presenting to Mardan Medical Complex, Mardan
}

Gohar Ali, Asghar Ali ${ }^{2}$, Ashfaq Hussain ${ }^{3}$, Ejaz Gul ${ }^{4}$, Muslim Muhammad ${ }^{4}$, Pirzada M. Muneeb $^{5}$, Sumaira $^{5}$ ABSTRACT

Background: Chronic pain accompanies emotional element in the form of psychiatric disorders. Chronic medical conditions such as backache may make a person at higher risk for depression. Depressed patients also have somatic symptoms as headache, fatigue, and backache. To understand the relationship, we conducted this study at neurosurgery Outpatient department of Mardan medical complex, Mardan.

Objective: The aim of this study was to clarify the causal relationship of backache and depression. The study also aimed to explore the frequency of depression among patients with backache.

Material and Methods: This cross-sectional study was conducted at outpatient department of Mardan Medical Complex. Patients presenting with chief complaints of backache were invited for participation in the study. initial medical and neurological screening was conducted by consultant neurosurgeon and afterwards HAM-D was administered for assessment of depression.

Results: We included 114 male and female patients ranging in age from 22 to 58 years, who presented to neurosurgery OPD with chief complaints of backache. More than half $58 \%$ of the patients were female. Minimal depression was found among $22(19.3 \%)$ of the patients, $19(16.7 \%)$ patients had mild depression, $47(41.2 \%)$ had moderate depression, and $26(22.8 \%)$ had severe depression. Highest frequency of depression was observed among patients with infection/ tumor (84.5\%) and those with degenerative backache $(79 \%)$. The correlation of type of backache and severity of depression was significant $(p=.049)$.

Conclusion: Depression is common among patients with backache, therefore screening patients with complaints of backache for psychiatric co morbidity in primary care is important because psychopathology may have significant consequences for prognosis, outcome and health care utilization.

Keywords: Depression, Chronic Backache, infection tumor, Degenerative backache

This article may be cited as: Ali G, Ali A, Hussain A, Gul E, Muhammad M, Muneeb PM.

Frequency of Depression among Patients with Backache presenting to Mardan Medical Complex, Mardan. J Saidu Med Coll Swat 2020;10(2): 150-155

\section{INTRODUCTION}

Back pain is considered as one of the most common medical problems affecting people of different ages throughout the world. It is the most commonly reported type of pain followed by headache and knee pain 1. According to estimates, $60-80 \%$ of people experience back pain once in their lives, among these $30-40 \%$ experience pain every year ${ }^{2}$. It can cause disability and cause impairment in daily life functioning and performance of a person ${ }^{3}$, the incidence of chronic back pain has been reported to be $9-21 \%$ in general population and is gradually increasing with the passage of time ${ }^{4}$.

International Association for the Study of Pain defines pain as an unpleasant sensory and emotional experience associated with actual or potential tissue damage or is described in terms of

\section{Mardan Medical Complex, Neurosurgery Unit,}

Mardan Medical Complex

2.District Specialist, Neurosurgery Unit, Mardan Medical Complex

3.Department of Psychiatry, Saidu Medical College, Swat

4.Bacha Khan Medical College, Psychiatry Unit,

Mardan Medical Complex

5.Clinical Psychologist, Department of Psychiatry,

Mardan Medical Complex

Correspondence: Dr. Ejaz Gul Associate Professor,

Bacha Khan Medical College,

Psychiatry Unit, Mardan Medical Complex such damage ${ }^{5}$. Chronic pain is commonly reported; although it is mainly a somatic symptom, it might also have a devastating emotional element ${ }^{6}$.

Chronic back pain and depression are two terrible problems that present in health establishment. Back pain is a biological condition that mostly present with the patient physical symptoms while depression is a psychiatric condition ${ }^{7}$. The physical and psychological distress of chronic pain in association with individual and social vulnerability may results in the development of episode of major depression ${ }^{8}$.

Pain and depression share biological pathways and nerve transmitters for both conditions in implication area of treatment. Assessment and treatment of severe back pain and depression both coextensive are necessary for fruitful outcomes ${ }^{9}$.

Physicians dealing with pain focus primarily on etiologic cause of a patient's pain. However, pain is a subjective experience, in which important role is played by the emotional states in the development of the pain ${ }^{5}$. Studies suggest that emotional stress acts as a contributor to pain and its perception ${ }^{10}$. Back pain is consistently associated to depression in various studies. Research has suggested that people suffering

Received: October 28, 2019 Accepted: July 27, 2020 
from depression are $60 \%$ more likely to develop back pain in lifetime as compared to the general population ${ }^{11}$.

Depression is an illness that may worsen the prognosis of low back pain and in the primary care, it is mostly considered as under recognized and under treated. Depression is common among patients with backache and is connected with the high intensity of pain, increased biological and psychological disability, increased likelihood of unemployment, and increased medication use. Although still, it is not established whether depression is the cause or result of backache, but it is clear that depression is associated with poor outcomes and impaired daily life functioning ${ }^{13}$. With the help of the current study, we aim to clarify the relationship between depression and backache, in order to help neurosurgeons, and ortho specialists better manage patients with primary complaints of backache.

\section{MATERIALAND METHODS}

This study was a cross sectional study and included patients presenting to neurosurgery Outpatient department of a tertiary care hospital located in district Mardan. The topic of the study was discussed thoroughly in ethical committee meeting held in Bacha Khan medical college, Mardan. The topic was reviewed and permission for data collection was given. The study started in February 2019 and was completed in August 2019. Those patients fulfilling the inclusion criteria of the study were asked for participation in the study. Informed consent was obtained, and necessary information was obtained through demographic information sheet devised for data collection. Medical and neurosurgical examination was conducted by consultant neurosurgeon and those fulfilling study criteria were further referred to psychologist for interview and screening for depression. At the end thanks was paid to the participants.

\section{Inclusion and exclusion criteria}

Those male and female patients who presented with principal complaint of backache were included in the study. All those patients were excluded from the study who had comorbid medical illness, including Hypertension, diabetes, Acute head injury (occurring 20 days ago), poly head injuries, those having cognitive deficits (poor attention, loss of consciousness), agitated and those not willing to participate in the study were excluded. The exclusion was made in order to minimize the effects of other extraneous variables impact on levels of depression.

\section{Measures}

Initial medical and neurosurgical examination was conducted by consultant neurosurgeon. Those who were suspected having neurological condition were referred for MRI and CT scan to assess neurological illness. Backache was classified on the base of clinical examination by consultant neurosurgeon. Complaints of backache were categorized as simple backache, post-traumatic, degenerative, and infection/tumor. Afterwards, Semi-structured interview was conducted to obtain demographic information, and ascertain the presence of depression.

\section{Hamilton Depression Rating Scale}

Hamilton Depression Rating Scale was used to assess severity of symptoms of depression among patients presenting with complaints of backache. HAM-D is clinician rating scale widely used to assess severity of symptoms of depression in clinical trials. HAM-D includes 21 items designed to measures severity of depression among those diagnosed as depressed ${ }^{14}$. The scores range from 0 to 62 . Score ranging from 0-7 indicates Normal, 8-13 mild depression, 14-18 moderate depression, 19-22 severe depression and $>23$ very severe depression.

\section{Data Analysis}

Data was analyzed using SPSS version 21. Cross tabulation was used to explain comparison for diagnosis of backache, gender and severity of depression.

\section{RESULTS}

Table 1. shows important demographic details of patients with backache, the patients in our study included 114 male and female ranging in age from 22 to 58 years of age. More than half $58 \%$ of the patients were female. Majority were married (62.8 $\%)$. More than $55 \%$ were non-working among the patients. Among the study participants, 36 (31.6\%) had simple backache, 28 (24.6\%) had 
post-traumatic backache, $24(21 \%)$ had degenerative backache, and 26 (22.8\%) had infection/ Tumor. Minimal depression was found among $22(19.3 \%)$ of the patients, $19(16.7 \%)$ patients had mild depression, $47(41.2 \%)$ had moderate depression, and $26(22.8 \%)$ had severe depression.

Table 1. Demographic details of study important variables

Table 1. Demographic details of study important variables

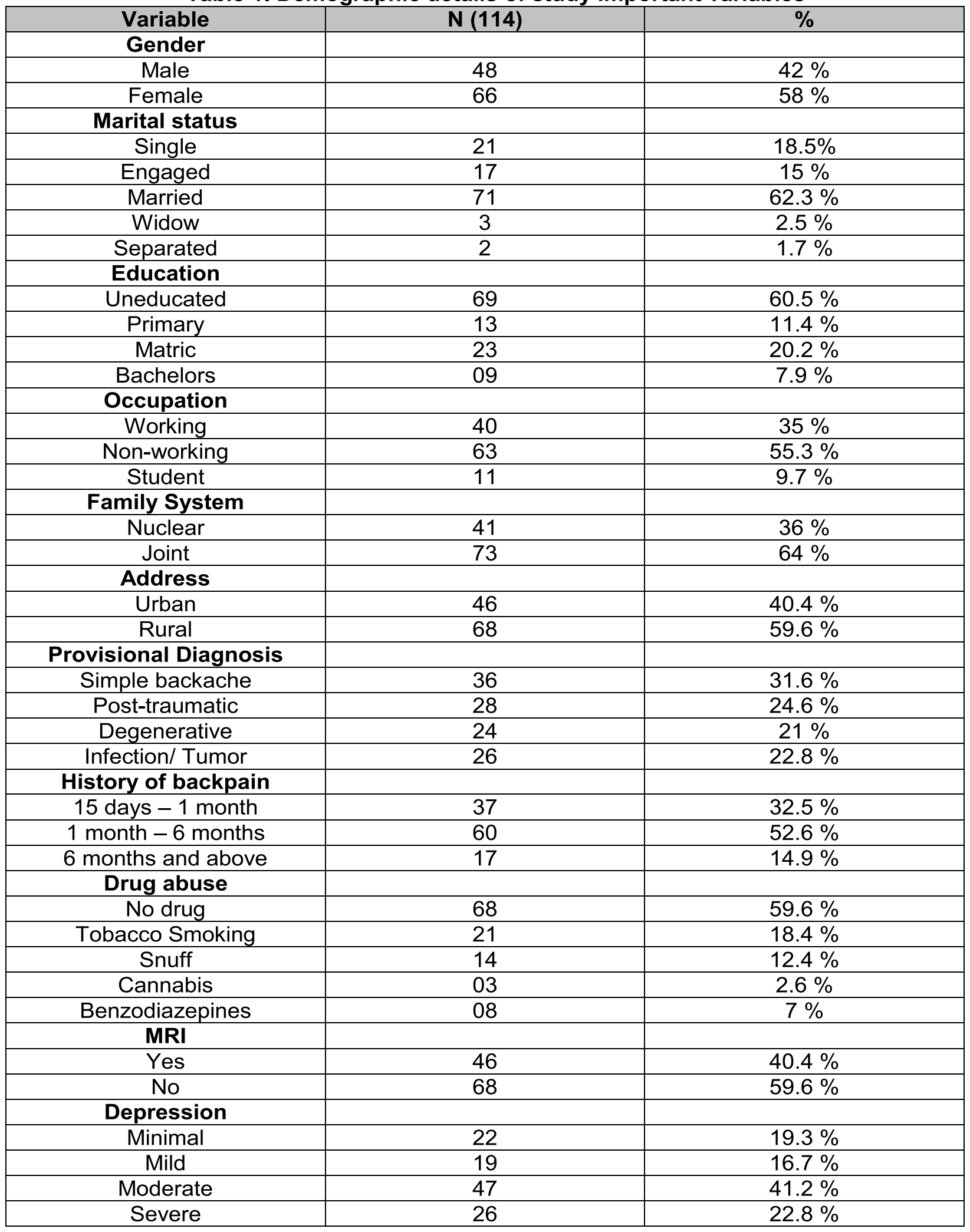


Table 2. Cross tabulation of diagnosis and severity of depression

\begin{tabular}{|c|c|c|c|c|c|}
\hline & $\begin{array}{c}\text { Minimal } \\
\text { Depression }\end{array}$ & $\begin{array}{c}\text { Mild } \\
\text { Depression }\end{array}$ & $\begin{array}{c}\text { Moderate } \\
\text { Depression }\end{array}$ & $\begin{array}{c}\text { Severe } \\
\text { Depression }\end{array}$ & Total \\
\hline $\begin{array}{c}\text { Simple } \\
\text { Backache }\end{array}$ & 09 & 11 & 14 & 02 & $36(31.6 \%)$ \\
\hline Post traumatic & 07 & 05 & 12 & 04 & $28(24.6 \%)$ \\
\hline Degenerative & 03 & 02 & 07 & 12 & $24(21 \%)$ \\
\hline $\begin{array}{c}\text { Infection/ } \\
\text { Tumor }\end{array}$ & 03 & 01 & 14 & 08 & $26(22.8 \%)$ \\
\hline Total & $22(19.3 \%)$ & $19(16.7 \%)$ & $47(41.2 \%)$ & $26(22.8 \%)$ & 114 \\
\hline
\end{tabular}

Table 3. Correlation of Diagnosis and severity of depression Correlations

\begin{tabular}{|cc|c|c|}
\hline & & $\begin{array}{c}\text { Provisional } \\
\text { Diagnosis }\end{array}$ & BDI Scores total \\
\hline \multirow{2}{*}{ Provisional Diagnosis } & Pearson Correlation & 1 & $.197^{*}$ \\
& Sig. (2-tailed) & & .049 \\
& $\mathrm{~N}$ & 114 & 114 \\
BDI Scores total & Pearson Correlation & $.197^{*}$ & 1 \\
& Sig. (2-tailed) & .049 & 114 \\
\hline
\end{tabular}

${ }^{*}$. Correlation is significant at the 0.05 level (2-tailed).

Table 4. Cross tabulation of Gender and severity of depression

\begin{tabular}{|l|l|l|l|l|l|}
\hline & $\begin{array}{l}\text { Minimal } \\
\text { Depression }\end{array}$ & $\begin{array}{l}\text { Mild } \\
\text { Depression }\end{array}$ & $\begin{array}{l}\text { Moderate } \\
\text { Depression }\end{array}$ & $\begin{array}{l}\text { Severe } \\
\text { Depression }\end{array}$ & Total \\
\hline Male & 05 & 11 & 20 & 12 & $48(42.1 \%)$ \\
\hline Female & 17 & 08 & 27 & 14 & $66(57.9 \%)$ \\
\hline Total & 22 & 19 & 47 & 26 & 114 \\
\hline
\end{tabular}

Table 5. Correlation of gender and severity of depression Correlations

\begin{tabular}{|ll|l|l|}
\hline & & BDI Scores total & Gender of Patient \\
\hline \multirow{3}{*}{ BDI Scores total } & Pearson Correlation & 1 & -.032 \\
& Sig. (2-tailed) & & .749 \\
& $\mathrm{~N}$ & 114 & 114 \\
& Pearson Correlation & -.032 & 1 \\
Gender of Patient & Sig. (2-tailed) & .749 & \\
& $\mathrm{~N}$ & 114 & 114 \\
\hline
\end{tabular}

Table 2 shows cross tabulation of diagnosis of backache and depression among the study population. Our findings show that depression was most prevalent among patients with infection or tumor and those with degenerative backache. Among the 28 patients with post traumatic backache, $16(57 \%)$ had depression. While 22 $(84.5 \%)$ out of 26 patients with infection or tumor were found to be depressed. Of the 36 patients with simple backache, $16(44.4 \%)$ were found to be lying in the range of moderate to severe depression. Among the 24 patients with degenerative backache, $19(79 \%)$ were found to be lying in the range of moderate to severe depression. 
Table 3 shows correlation significance of diagnosis and severity of depression. The correlation is significant $(p=.049)$.

Table 4 shows cross tabulation of gender wise frequency of depression among the patients. Among the 48 males, $32(66.6 \%)$ lied in the range of moderate to severe depression. While among the 66 females, $41(62 \%)$ lied in the range of moderate to severe depression.

Table 5 shows correlation significance of gender and severity of depression. The correlation is not significant.

\section{DISCUSSION}

Our study shows that Moderate depression was present among $47(41.2 \%)$ of the patients, while severe depression was present among 26 (22.8 $\%)$ of the patients. Combining rates of moderate and severe depression makes $73(64 \%)$ of the patients falling in the category of depression according to DSM 5 criteria of depression. The mean prevalence of co morbid major depression is reported to be $52 \%$ in pain clinics ${ }^{15}$. Kim et al. assessed 97 Korean patients with spinal stenosis employing the beck depression inventory (BDI) and found that the scores of depression were above the threshold for depression among 54 of the patients $(55.7 \%)^{16}$.

Our study shows that backache was more common among married individuals. Majority of the patients $71(62.3 \%)$ were married followed by $21(18.5 \%)$ patients were single.

Studies from the past also have found higher rates of depression among patients with back pain. A study form Karachi examining depression among patients with chronic low back pain found depression to be present among $49 \%$ of the patients. The study also found that the risk for depression among females was higher as compared to males ${ }^{17}$. Another recent study also found depressive mood among $51.3 \%$ of the patients with complaints of chronic low back pain, this study added that female gender was a risk factor for developing depression among this population ${ }^{18}$. Our results also showed that more females participants (41) were depressed as compared to males (32). Comparison was made based on moderate to severe depression scores on HAM-D.
A recent study from India conducted in a tertiary care hospital found almost similar rates of depression that is $74 \%$ among patients with complaints of chronic low back pain ${ }^{19}$. Clinical samples of studies conducted in the past showed rates of depression ranging from $30 \%$ to $62.8 \%$ among this population ${ }^{20,21}$. A Nigerian study showed prevalence rate of depression to be 39.5 $\%$ among patients with backache ${ }^{7}$

Simple backache is very common in our study population, $31.6 \%$ of the patients had simple backache. Astudy examining data of World Health Survey on the prevalence of back pain found that the prevalence of back pain in Pakistan was 40.6 $\%$. Highest prevalence of $69.5 \%$ was recorded of Nepal, while lowest prevalence was $19.8 \%$ noted that of India ${ }^{22}$. A prevalence rate of $44 \%$ was observed from a study conducted in Islamabad assessing back pain among teachers ${ }^{23}$. Another recent large-scale study examining depression among chronic pain patients found that back pain was the most frequently reported (53.6\%) primary complaint among pains of other bodily regions, and among these patients $54.5 \%$ had depression 22,23 .

\section{CONCLUSION}

Co-existence of pain and depression is mostly underestimated and not properly understood in hospitals and health care facilities. The two conditions when comorbid may lead to worst physical and psychological functioning. It is suggested from the findings of current study that depression is very common among patients with backache therefore it is advised that screening patients with complaints of backache for psychiatric co morbidity in primary care is important to consider because psychopathology may have serious additional consequences for prognosis, outcome and health care utilization.

\section{REFERENCES}

1. Vrbaniæ TS. Kri obolja-od definicije do dijagnoze low back pain-from definition to diagnosis. Reumatizam. 2011;58(2):163-169.

2. Volinn $\mathrm{E}$. The epidemiology of low back pain in the rest of the world: a review of surveys in low-and middleincome countries. Spine. 1997 Aug 1;22(15):1747-54.

3. Tsang SM, Szeto GP, Li LM, Wong DC, Yip MM, Lee RY. The effects of bending speed on the lumbo-pelvic kinematics and movement pattern during forward bending in people with and without low back pain. BMC musculoskeletal disorders. 2017 Dec 1;18(1):1571-167. 
4. Sions JM, Coyle PC, Velasco TO, Elliott JM, Hicks GE. Multifidi muscle characteristics and physical function among older adults with and without chronic low back pain. Archives of physical medicine and rehabilitation. 2017 Jan 1;98(1):51-7.

5. Classification of chronic pain. Descriptions of chronic pain syndromes and definitions of pain terms. Prepared by the International Association for the Study of Pain, Subcommittee on Taxonomy. Pain Suppl. 1986;3:S1 -S226.

6. Sykioti P, Zis P, Vadalouca A, Siafaka I, Argyra E, Bouhassira D, etal. Validation of the Greek Version of the DN 4 Diagnostic Questionnaire for Neuropathic Pain. Pain Practice. 2015 Sep;15(7):627-32.

7. Namgwa KJ, Terkura A, William Y, Daniel MD, Cornilius El. Depression in patients with chronic low back pain: a hospital-based study. Nigerian Journal of Surgical Research.2016; 17:1-9.

8. Pinheiro $M B$, Ferreira $M L$, Refshauge $K$, Ordoñana JR, Machado GC, Prado LR, etal. Symptoms of depression and risk of new episodes of low back pain: a systematic review and meta-analysis. Arthritis care \& research. 2015 Nov;67(11):1591-603.

9. Søndergård S, Vaegter HB, Erlangsen A, Stenager E. Ten-year prevalence of mental disorders in patients presenting with chronic pain in secondary care: A register linkage cohort study. European Journal of Pain. 2018 Feb;22(2):346-54.

10. Macfarlane TV, Kincey J, Worthington HV. The association between psychological factors and orofacial pain: a community-based study. European Journal of Pain. 2002 Dec 1;6(6):427-34.

11. Pinheiro MB, Ferreira ML, Refshauge K, Maher CG, Ordoñana JR, Andrade TB etal. Symptoms of depression as a prognostic factor for low back pain: a systematic review. The Spine Journal. 2016 Jan 1;16(1):105-16.

12. Gureje O, Simon GE, Von Korff M. A cross-national study of the course of persistent pain in primary care. Pain. 2001 May 1;92(1-2):195-200.

13. Haggman S, Maher CG, Refshauge KM. Screening for symptoms of depression by physical therapists managing low back pain. Physical therapy. 2004 Dec 1;84(12):1157-66.

14. Hamilton M. A rating scale for depression. Journal of neurology, neurosurgery, and psychiatry. 1960 Feb;23(1):56-61.
15. Bair MJ, Robinson RL, Katon W, Kroenke $\mathrm{K}$. Depression and pain comorbidity: a literature review. Archives of internal medicine. 2003 Nov 10;163(20):2433-45.

16. Kim AR, Seo BB, Kim JM, Bae JI, Jang YH, Lee YC, etal. Beckdepression inventoryscore andassociated factors in Korean patients with lumbar spinal stenosis. The Korean Journal of Pain. 2007;20(2):138-42.

17. Sagheer MA, Khan MF, Sharif S. Association between chronic low back pain, anxiety and depression in patients at a tertiary care centre. J Pak Med Assoc. 2013 Jun 1;63(6):688-90.

18. Kakpovi K, Soedje KM, Koffi-Tessio VE, Ahoble KE, Fianyo E, Houzou $P$ etal. Anxiety and depression disorders in chronic non-specific low back pain in Lomé (Togo). Open Journal of Rheumatology and Autoimmune Diseases. 2017;7(01):1-5.

19. Srivastava S, Yadav P, Panchal BN, Vala AU, Ratnani I, Khania P. Association of depression and chronic lower-back pain. Archives of Psychiatry and Psychotherapy. 2018 Dec 1;4:37-46.

20. Banks SM, Kerns RD. Explaining high rates of depression in chronic pain: A diathesis-stress framework. Psychological bulletin. 1996 Jan;119(1):95-101

21. Bishwajit G, Tang S, Yaya S, Feng Z. Participation in physical activity and back pain among an elderly population in South Asia. Journal of Pain Research. 2017; 10:905-911.

22. Waqas $M$, Ghaffar $T$, Javed $H$, Siddique $S$, Javed $A$. Study to Find Out the Frequency of Low Back Pain and Its Associated Factors among Boys College Teachers of Twin Cities (Rawalpindi and Islamabad), Pakistan. Physiother Rehabil. 2017;2(1). DOI:10. 4172/25730312. 1000130.

23. Rayner L, Hotopf M, Petkova H, Matcham F, Simpson A, McCracken LM. Depression in patients with chronic pain attending a specialised pain treatment centre: prevalence and impact on health care costs. Pain. 2016 Jul;157(7):1472-1481. 